\title{
Al Microheater and Ni Temperature Sensor Set based-on Photolithography with Closed-Loop Control
}

\author{
Pittaya Deekla*, Rungrueang Phatthanakun**, Sarawut Sujitjorn**, Nimit Chomnawang* \\ * School of Electrical Engineering, Institute of Engineering, Suranaree University of Technology, \\ Nakhon Ratchasima 30000, Thailand \\ ** Synchrotron Light Research Institute (Public Organization), Nakhon Ratchasima 30000, Thailand
}

\begin{tabular}{|c|c|}
\hline Article Info & ABSTRACT \\
\hline Article history: & This article proposes the development of a new low-cost microheater and \\
\hline Received Apr 3, 2015 & Systems (MEMS) which based on photolithography technique and lift-off \\
\hline Revised May 26, 2015 & technique. Thin film of aluminum was utilized as microheater and \\
\hline Accepted June 8, 2015 & $\begin{array}{l}\text { encompassed nickel temperature sensor inside in order to decrease response } \\
\text { time of the desired temperature. To control the various temperatures }\end{array}$ \\
\hline Keyword: & $\begin{array}{l}\text { correctly, closed-loop feedback control based on PI-controller was adapted } \\
\text { into control circuit system. Microcontroller was implemented to control and }\end{array}$ \\
\hline Closed-loop control & observe the responses of temperature between $40^{\circ} \mathrm{C}$ and $120^{\circ} \mathrm{C}$. Simulation \\
\hline MEMS & \\
\hline Microheater & \\
\hline Photolithography & \\
\hline Temperature sensor & $\begin{array}{r}\text { Copyright (C) } 2015 \text { Institute of Advanced Engineering and Science. } \\
\text { All rights reserved. }\end{array}$ \\
\hline \multicolumn{2}{|l|}{ Corresponding Author: } \\
\hline \multicolumn{2}{|c|}{$\begin{array}{l}\text { Pittaya Deekla, } \\
\text { School of Electrical Engineering, Institute of Engineering, } \\
\text { Suranaree University of Technology, } \\
111 \text { University Avenue, Muang, Nakhon Ratchasima 30000, Thailand } \\
\text { Email: pittayadeekla@gmail.com }\end{array}$} \\
\hline
\end{tabular}

\section{INTRODUCTION}

Nowadays, a number electronic devices offer multi-functional operation serving user requirements which can be integrated into a single chip and embedded inside an instrument. Based on the fabrication of integrated circuits (ICs) technology, micro-sensors and micro-actuators can be fabricated using technology called Micro-Electro-Mechanical Systems (MEMS). Several micro-scale components which interact with outside environment can be fabricated by deposition of material layers, photolithographic patterning, and etching to create the desired profiles. MEMS is generally based on micro-fabrication which is made up of components between $1-1000$ micrometers in size, resulting in MEMS devices with the size ranging from 20 micrometers to millimeters. Many actuators and sensors such as micromotors, micropumps, microvalves, microheaters, temperature sensors, and humidity sensors are applied to microdevice for implementation of their functions.

Sensor is one of the important applications which has been usually applied with the temperature set. Gas sensor is usually integrated with microheater and temperature sensor in order to control uniformity and heating temperature at the whole region of gas sensing [1]-[4]. The temperature set has also been commonly used in microfluidic system [5] such as lab-on-a-chip with polymerase chain reaction (PCR) which is a function to control the thermal cycling for DNA amplification [13]-[19]. Moreover, micropump and microvalve which are applied to drive solutions in microchannels embedded in the chip can be operated by using MEMS actuator.

At present, microheater and temperature sensor which are usually integrated in a single chip have been developed continuously in MEMS technology. However, high cost is one of the most serious problems 
because of their complicated fabrication processes such as chemical etching [2], lift-off process [6]-[7], reactive ion etching (RIE) process [3],[8],[9], and PECVD/LPCVD [13]-[15]. These processes are also faced with many expensive chemicals and materials. Another important factor is the material selection for the design and fabrication of the micro heaters and sensors. A lot of research works have been using platinum [13]-[17], copper [11],[19] and gold [18] to fabricate microheaters and sensors due to their accuracy and stability for extensive applications. Not only their costs are expensive but operating temperature ranges are also wider than some required application. Table 1 shows the properties and prices of materials which have been applied for microheater and temperature sensor (www.metalprices.com and www.ptable.com).

Table 1. Properties and prices of materials

\begin{tabular}{|c|c|c|c|c|}
\hline Material & $\begin{array}{l}\text { Resistivity }(\Omega \cdot \mathrm{m}) \text { at } \\
20^{\circ} \mathrm{C}\end{array}$ & $\begin{array}{l}\text { Temperature coefficient of } \\
\text { resistance (TCR) }\left(\mathrm{C}^{-} 1\right)\end{array}$ & Prices (USD/lb) & $\begin{array}{c}\text { Sensor temperature } \\
\text { range }\end{array}$ \\
\hline Aluminum & $2.82 \times 10^{8}$ & 0.0045 & 1.17 & $-40^{\circ} \mathrm{C}$ to $160^{\circ} \mathrm{C}$ \\
\hline Copper & $1.68 \times 10^{8}$ & 0.0043 & 4.24 & $-100^{\circ} \mathrm{C}$ to $260^{\circ} \mathrm{C}$ \\
\hline Nickel & $6.99 \times 10^{8}$ & 0.0067 & 11.61 & $-80^{\circ} \mathrm{C}$ to $260^{\circ} \mathrm{C}$ \\
\hline Gold & $2.44 \times 10^{8}$ & 0.0040 & 22688.00 & $-150^{\circ} \mathrm{C}$ to $300^{\circ} \mathrm{C}$ \\
\hline Platinum & $10.6 \times 10^{8}$ & 0.0039 & 28398.40 & $-200^{\circ} \mathrm{C}$ to $800^{\circ} \mathrm{C}$ \\
\hline
\end{tabular}

The selection of materials for microheater is considered from the minimum temperature coefficient of resistance (TCR) to reduce the effect of the temperature resistance changing from the input power. In contrast with temperature sensor, material with the maximum temperature coefficient of resistance and a linear positive change in resistance with respect to temperature are considered. However, the manufacturing cost is still expensive if the applied devices have to be operated at high temperature $\left(>300^{\circ} \mathrm{C}\right)$ because of the cost of fabrication process. The PCR chip and some actuators such as micropump and microvalve operate at temperature lower than $150^{\circ} \mathrm{C}$, which suggests the choice of fabricated materials for economic cost. In low temperature system, nickel which provides the best sensitivity can be chosen to be the temperature sensor operated from $-100^{\circ} \mathrm{C}$ to $260^{\circ} \mathrm{C}$, while aluminum can be applied as microheater to support the temperature higher than $100^{\circ} \mathrm{C}$ which is sufficient to cover every working condition.

To control the heating temperature of microheater on the microfluidic chip, a lot of researches have been performed by applying open-loop control since it is simple but inaccurate [2],[6],[7]. By applying current to microheater, the temperature is increased continuously without any monitoring. The microdevices on the chip which are always controlled by this method are microvalve and micropump [20]-[22]. To improve temperature accuracy of heating, thin-film sensors have been integrated as resistance temperature detector (RTD) by being placed at the sensing area. The sensors offer a linear positive resistance changing with respect to temperature which is suitable to apply to a closed-loop control system. Generally, the closedloop control system has many methods such as ON-OFF or bang-bang control but both are not appropriate due to the oscillation in steady state. In addition, fuzzy-logic and PI/PID closed-loop control which are used for temperature control can be efficiently applied for feedback control with a step response [13],[19].

In this work aluminum ( $\mathrm{Al})$ microheater and nickel $(\mathrm{Ni})$ temperature sensor are constructed on a glass substrate because of their low thermal conductivity and high electrical resistance. Thin PDMS membrane is coated to protect them from environmental hazards. Nickel resistance is calibrated directly by temperature of microheater to estimate its characteristics. These resistance signals are adjusted to temperature values and fed-back to control microheater temperature through PI controller which is designed by a frequency domain method. To show the capability in the low temperature application, temperature ranging from $40^{\circ} \mathrm{C}$ to $120^{\circ} \mathrm{C}$ is controlled by using microcontroller with PI closed-loop control system.

\section{DESIGN AND FABRICATION}

The diagram in Figure 1 represents the fabrication process sequence of $\mathrm{Al}$ microheater and $\mathrm{Ni}$ temperature sensor on a glass substrate [23]. Firstly, the fabrication of microheater based on the glass slide by deposition of Al layer using thermal evaporation is shown in Figure 1(a). The AZ1512 positive photoresist was coated for a protective layer and patterned by UV lithography as shown in Figure 1(b). Next, the Al microheater pattern was appeared after etching in HF solution as shown in Figure 1(c) and the layer of AZ1512 was next covered again to create the sensor pattern as shown in Figure 1(d). After photoresist was patterned using UV lithography as shown in Figure 1(e), Ni was thermal-evaporated into the sensor pattern as shown in Figure 1(f). To leave Ni pattern on the substrate AZ photoresist was removed by a lift-off technique which utilized acetone to dissolve the photoresist, resulting in $\mathrm{Ni}$ sensor surrounded by $\mathrm{Al}$ microheater as 
shown in Figure 1(g). Finally, thin-film of PDMS was spin-coated in order to perform as a protective layer as shown in Figure 1(h). A complete microheater set was measured its characteristics and displayed in Table 2 and Figure 2 which shows schematic diagram of microheater-sensor set consisting of an Al microheater surrounding a Ni RTD sensor. By applying a voltage across the two ends of the microheater, heat can be generated rapidly. Sensor which is encompassed with heat generator can always sense temperature change, resulting in high accuracy temperature by using feedback control.

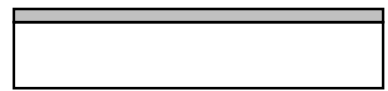

(a)

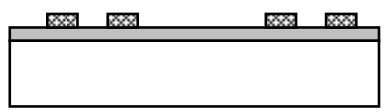

(b)

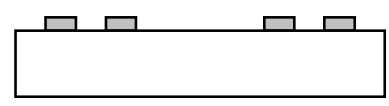

(c)

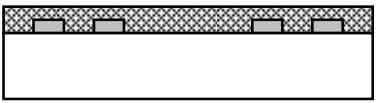

(d)

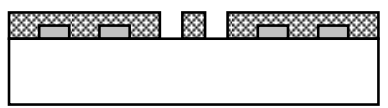

(e)

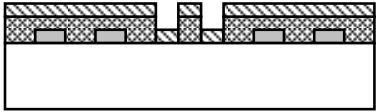

(f)

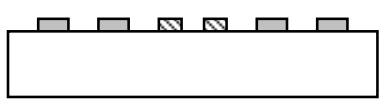

(g)

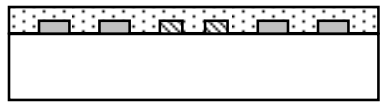

(h)

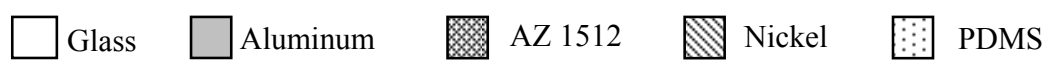

Figure 1. Fabrication sequence of microheater and temperature sensor

Table 2. Characteristics of microheater and temperature sensor

\begin{tabular}{ccccc}
\hline Material & Lengh $(L: \mathrm{mm})$ & Width $(w: \mu \mathrm{m})$ & Thickness $(t: \AA)$ & Resistance $(R: \Omega)$ \\
\hline Al (Heater) & 8.7 & 50 & 430 & 114 \\
Ni (Sensor) & 7.0 & 30 & 125 & 1427 \\
\hline
\end{tabular}

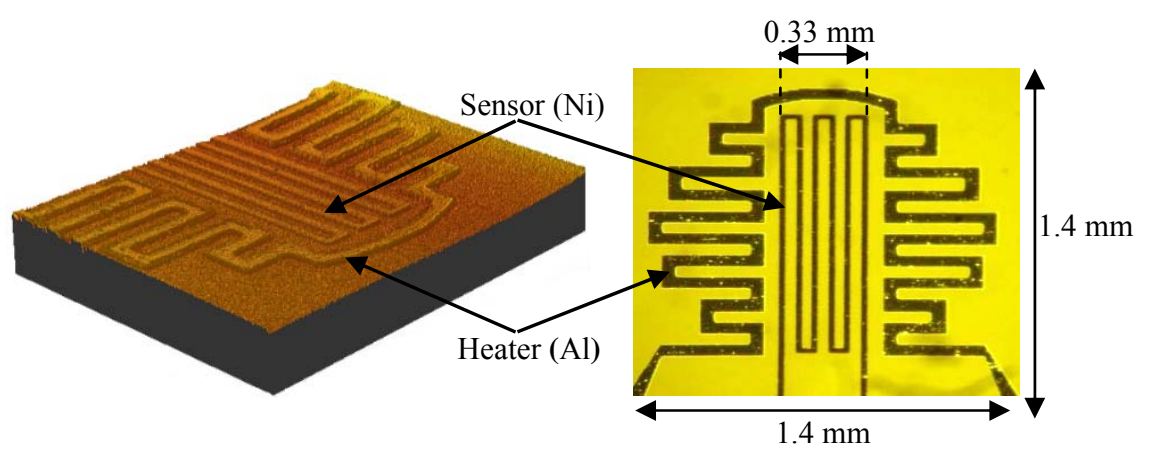

Figure 2. Structures of microheater and temperature sensor

\section{SENSOR CALIBRATION}

Calibration of the developed device utilizes an infrared camera FLIR-T360. This section describes the calibration circuits, procedures, and results, respectively. Figure 3 shows the schematic diagram of the calibration circuits consisting of the microheater-sensor set, a driver, an AVR microcontroller, a voltage divider, a zero-span circuit, and a low-pass filter. The driver uses a PN2222A transistor, which is driven by PWM (8 bit) signal generated by the AVR Atmega168/328 8-bit microcontroller. The main components of 
the signal conditioning circuits are the OPA4227 op-amps available from Texas Instruments. Design of these conditioning circuits follows standard design methods in textbooks, e.g. [24]. The AVR microcontroller reads the filtered signal through an on-chip A-to-D converter. Figure 4 shows practical setup of microheater-sensor set and calibration circuit.

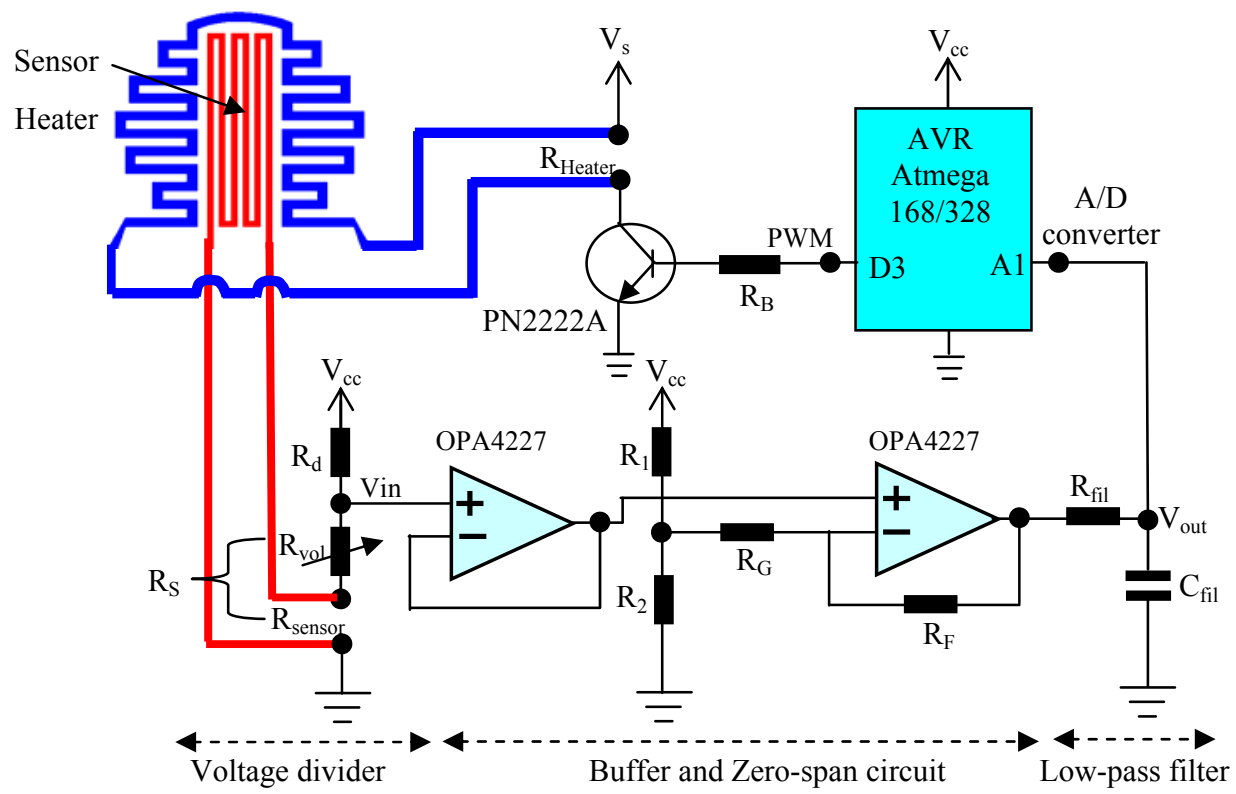

Figure 3. Schematic diagram of microheater-sensor set and calibration circuit

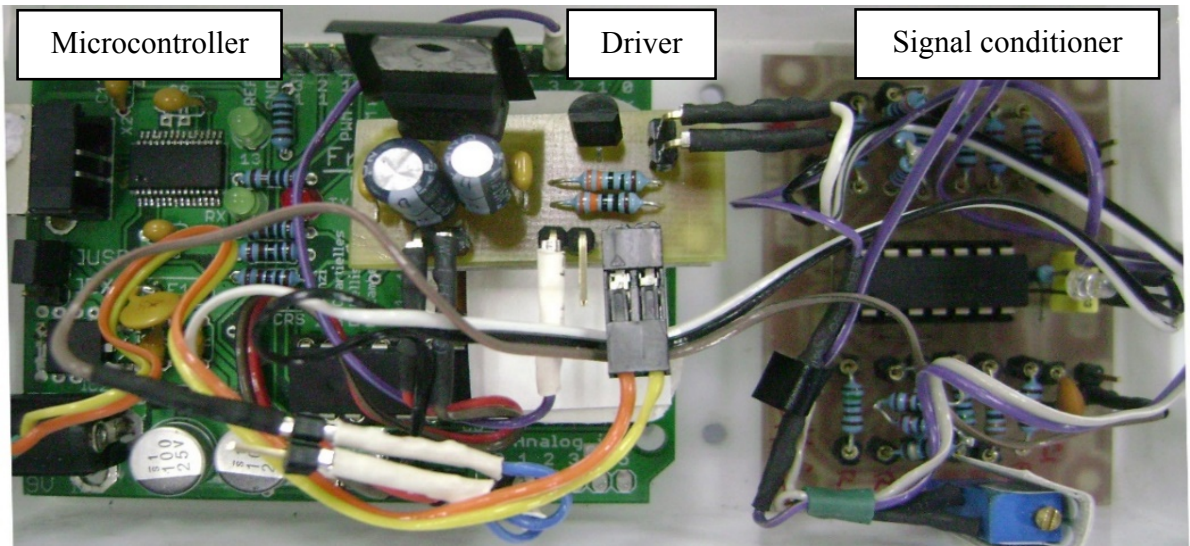

Figure 4. Practical setup of microheater-sensor set and calibration circuit

The sensor has its nominal resistance $R_{\text {sensor }}=1.427 \mathrm{k} \Omega$ at $25^{\circ} \mathrm{C}$. Therefore, a variable resistor is connected in series to the sensor to achieve a total resistance of $1.5 \mathrm{k} \Omega$, which is tuned to match the voltage divider. Temperature changes of $25^{\circ} \mathrm{C}$ to $140^{\circ} \mathrm{C}$ cause sensor-resistance variations around $0-500 \Omega(\Delta \mathrm{R})$. These correspond to output of the voltage divider of 2.5-2.82 V. The zero-span circuit adjusts this voltage range from $0.2 \mathrm{~V}$ to $4.0 \mathrm{~V}$ suitable for feeding an A-to-D converter. Table 3 summarizes the components used in these circuits.

To calibrate the sensor, the microcontroller generates various PWM codes to the driver. As a result, there are different current levels driving the sensor, resulting in different heat generated. Collection of the temperature data is monitored on an FLIR-T360 infrared camera. As an example, Figure 5(a) shows the picture seen on the camera screen. Figure 5(b) illustrates the equipment setup for calibration. Experiments were repeated for 10 times, and their average results are illustrated in Figure 6. 
Table 3. Components of the sensor calibration circuits

\begin{tabular}{cccc}
\hline Heater driver & Voltage divider & Zero-span & Low-pass filter \\
\hline $\mathrm{V}_{\mathrm{s}}=9 \mathrm{~V}$ & $\mathrm{~V}_{\mathrm{cc}}=5 \mathrm{~V}$ & $\mathrm{R}_{1}=1.277 \mathrm{k} \Omega$ & $\mathrm{R}_{\text {fil }}=100 \mathrm{k} \Omega$ \\
$\mathrm{R}_{\mathrm{B}}=330 \Omega$ & $\mathrm{R}_{\mathrm{d}}=1.5 \mathrm{k} \Omega$ & $\mathrm{R}_{2}=1.50 \mathrm{k} \Omega$ & $\mathrm{C}_{\text {fil }}=0.1 \mu \mathrm{F}$ \\
$\mathrm{R}_{\text {heater }}=114 \Omega$ & $\mathrm{R}_{\mathrm{vol}}=253 \Omega$ & $\mathrm{R}_{\mathrm{G}}=30 \mathrm{k} \Omega$ & \\
& $\mathrm{R}_{\text {sensor }}=1.427 \mathrm{k} \Omega$ & $\mathrm{R}_{\mathrm{F}}=330 \mathrm{k} \Omega$ & \\
\hline
\end{tabular}

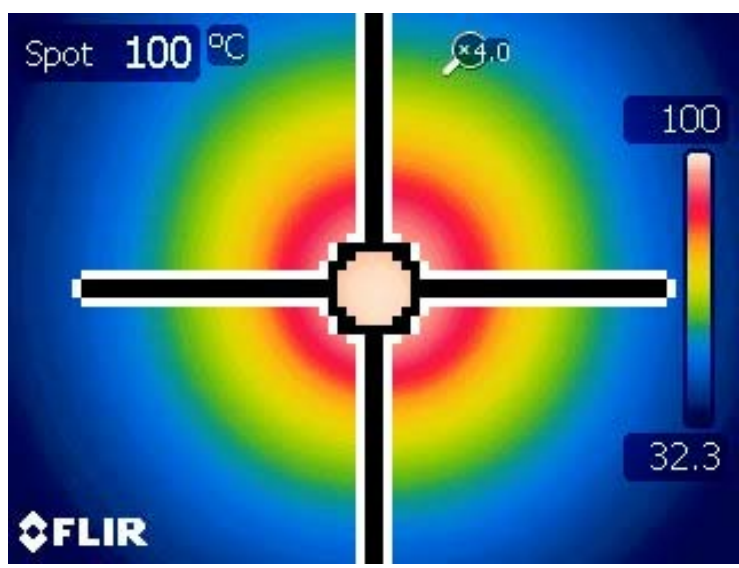

(a)

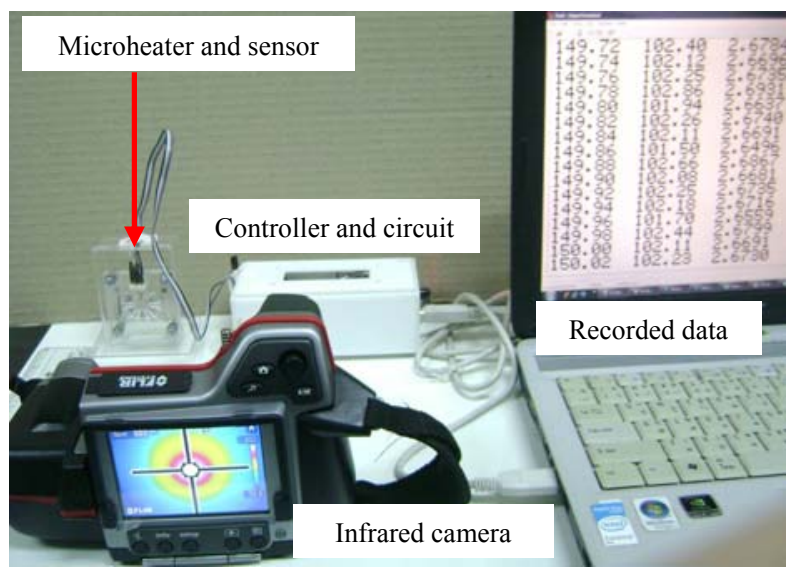

(b)

Figure 5. Setup of calibration equipment: (a) screen display of the infrared camera, (b) equipment setup

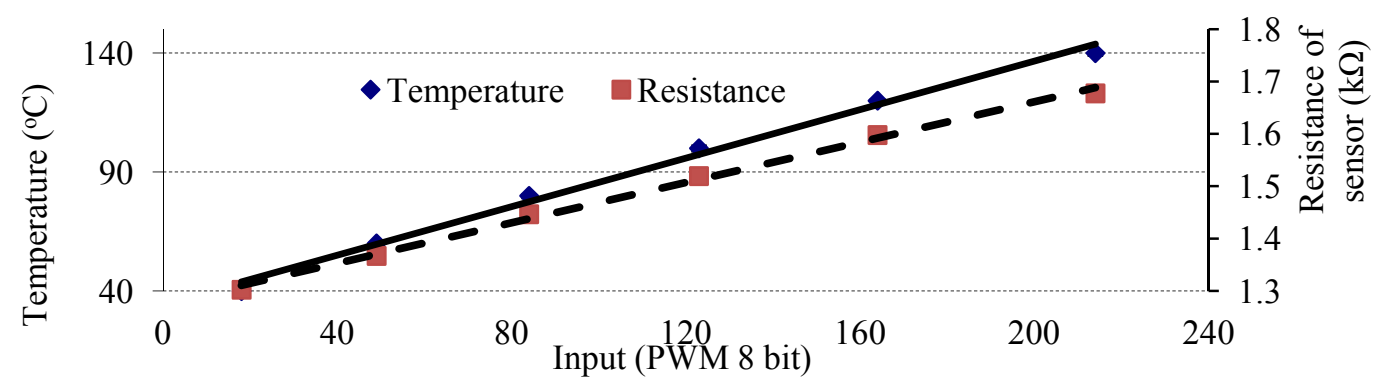

(a)

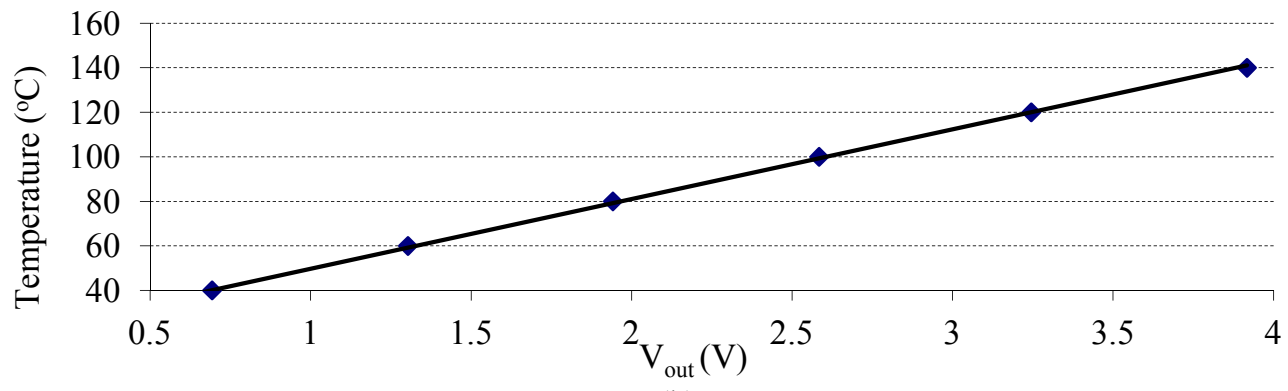

(b)

Figure 6. (a) Relationship between temperature-resistance and PWM codes, (b) Calibration curve

In Figure 6, linear relationships between temperatures, sensor resistances, PWM codes, and output voltages can be observed. Therefore, the temperature-voltage calibration curve can be represented by

$$
T=31.315 V_{\text {out }}+18.378
$$

Where $\mathrm{V}_{\text {out }}$ is the dc output voltage $(\mathrm{V})$ of the zero-span circuit, and $\mathrm{T}$ is the sensor temperature $\left({ }^{\circ} \mathrm{C}\right)$. 
During the calibration process, some dynamic characteristics of the developed sensors were observed and found that the settling time, in some cases, was as long as $100 \mathrm{~s}$. The slow response of the developed sensor can be drastically improved by a closed-loop control technique. Next section explains an approach using a PI-controller to improve the device response.

\section{CLOSED-LOOP CONTROL}

Closed-loop control development needs a model of the microheater. Regarding this, an empirical model has been used. We used MATLAB and System Identification Toolbox to identify a transfer function model of the ARMAX type [25]. Open-loop step-transient tests of the device were conducted as represented by the block diagram in Figure 7.

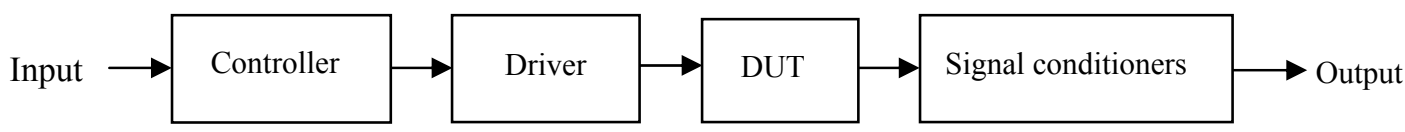

Figure 7. Diagram of open-loop control

For the tests, the temperature ranges are $40-140^{\circ} \mathrm{C}$ with a step of $20^{\circ} \mathrm{C}$. Figure 8 illustrates the step response curves whereas the PWM step command codes are embedded in the figure. The responses (numbered \#1, 2, 4 and 6) corresponding to $40^{\circ} \mathrm{C}, 60^{\circ} \mathrm{C}, 100^{\circ} \mathrm{C}$, and $140^{\circ} \mathrm{C}$, respectively, are normalized and used for identification. Validation of the obtained model is conducted against the normalized responses of $80^{\circ} \mathrm{C}$ and $120^{\circ} \mathrm{C}$. As a result, Figure 9 illustrates the identified model plotted against the normalized experimental responses. The root-mean-square errors of these results are 0.065 even though some steadystate errors still exist. The dc-gain of the model is adjusted to 1.01936 for eliminating the errors.

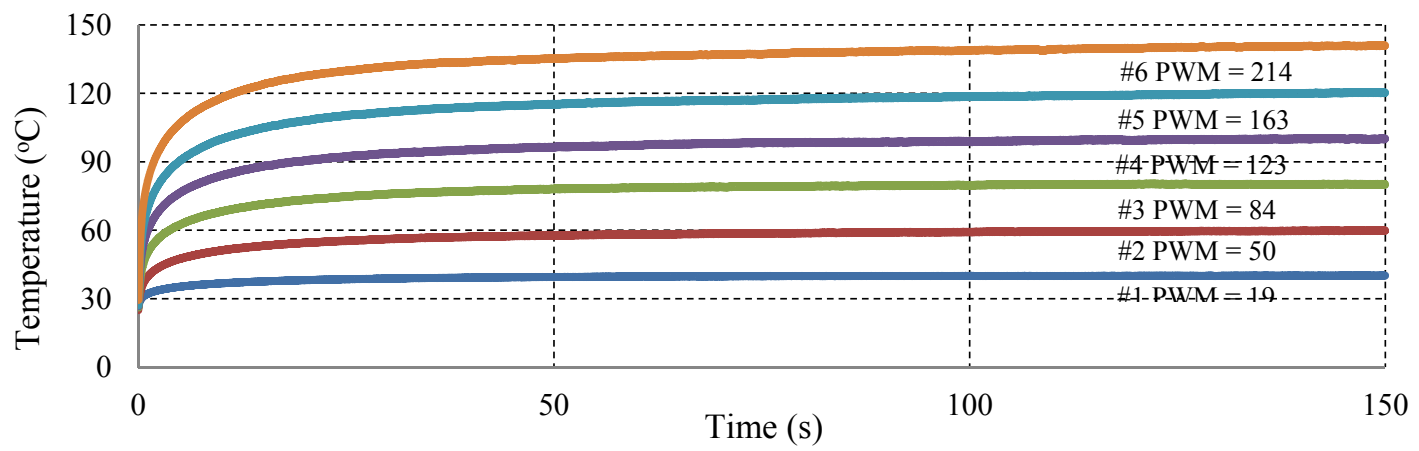

Figure 8. Open-loop step responses of the device

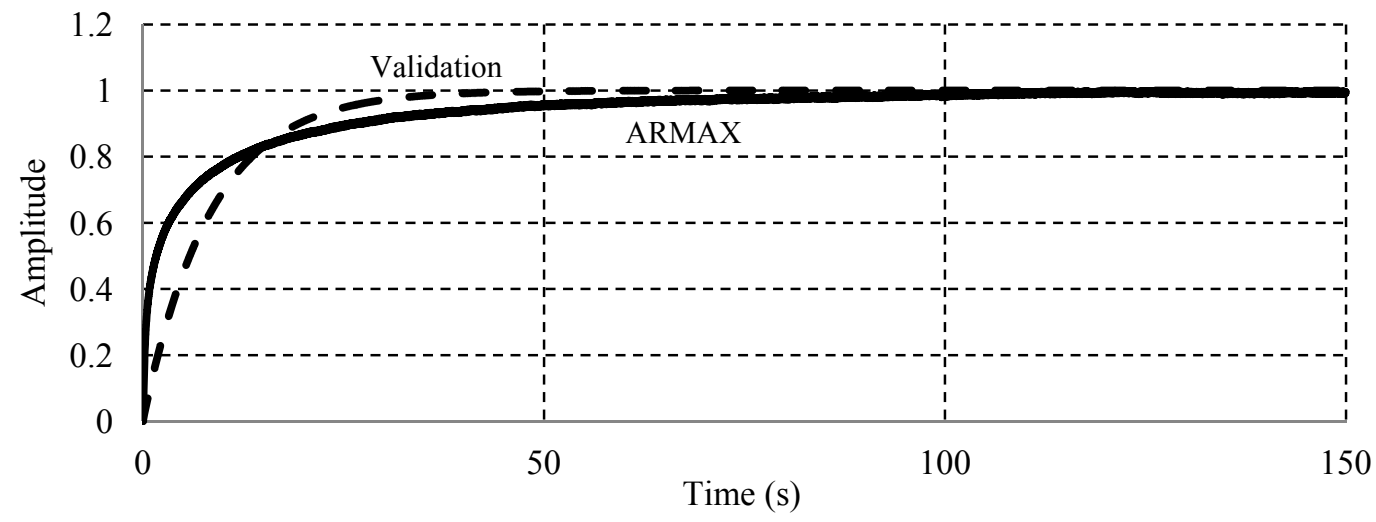

Figure 9. Validation results 
Therefore, the final model of the device is obtained in (2). Noticeably, the model indicates the settling time of $50 \mathrm{~s}$ while the actual response settles in $100 \mathrm{~s}$.

$$
G_{P}(s)=\frac{0.0012(s+100)}{s+0.1183}
$$

A conventional PI-controller followed a standard design procedure such as in [26] is used to improve the response of the device. The design is to achieve a required phase-margin of at least $50^{\circ}$. As a result, the control of the form in (3) has been obtained in which $\mathrm{Kp}=29.99$ and $\mathrm{Ki}=10.65$.

$$
G_{C}(s)=\frac{29.99 s+10.65}{s}
$$
function of (4)

Considering a unity-gain feedback system, the plant model (2), the controller (3) the system transfer

$$
G(s)=\frac{0.0355 s^{2}+3.562 s+1.26}{1.035 s^{2}+3.68 s+1.26}
$$

Figure 10 shows the simulated step response of the device with closed-loop control. Overshoot of less than $5 \%$ and settling time of less than $10 \mathrm{~s}$ are observed.

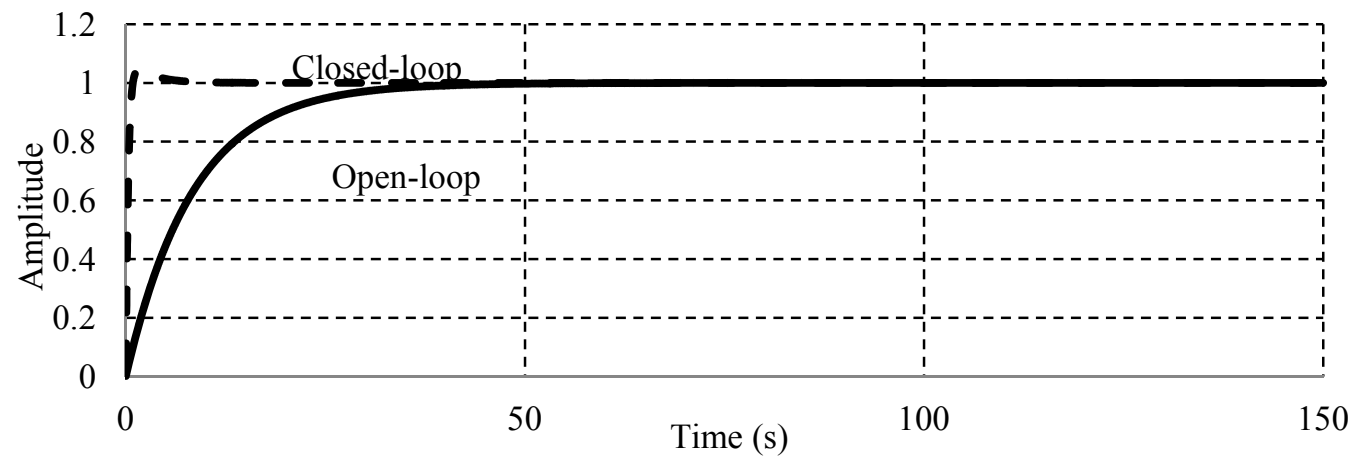

Figure 10. Simulated step response of the device with a PI-controller

\section{EXPERIMENTAL RESULTS}

The continuous-time controller of the form (3) has been discretized using Tustin's method.

\begin{tabular}{|c|c|}
\hline Program & Definitions \\
\hline $\mathrm{r}=$ setpoint $\mathrm{y}=$ output; & Define of setpoint and output \\
\hline $\mathrm{Kp}=$ conts $; \mathrm{Ki}=$ conts & Define of Kp gain and Ki gain \\
\hline Ui_1 $1=0$ & Initial value of I term \\
\hline err_- $1=0$ & Initial value of error \\
\hline $\mathrm{T}=$ conts & Define of sampling time \\
\hline while (1) & Action in loop forever \\
\hline$\{\quad$ err $=r-y$ & Calculate of error \\
\hline $\mathrm{Up}=\mathrm{Kp} * \mathrm{err}$ & Calculate of $\mathrm{P}$ term \\
\hline $\mathrm{Ui}=(\mathrm{Ki} * \mathrm{~T} / 2) *\left(\right.$ err+err_1) $+\mathrm{Ui} \_1$ & Calculate of I term \\
\hline $\mathrm{Upi}=\mathrm{Up}+\mathrm{Ui}$ & Sum of $P$ term and I term \\
\hline SentToDriver(Upi); & Sent value (PWM) of PI to driver \\
\hline $\mathrm{Ui} \_1=\mathrm{Ui}$ & Save variable of I term \\
\hline err_1 = err; & Save variable of error \\
\hline
\end{tabular}
Implementation of the controller uses an 8-bit AVR microcontroller as represented by the code-list in Table 4

Table 4. PI controller

Al Microheater and Ni Temperature Sensor Set based-on Photolithography with Closed-Loop ... (P. Deekla) 
Figure 11 illustrates the experimental results of the closed-loop control of the proposed device. The top left inset shows the whole step response for $100^{\circ} \mathrm{C}$ consisting of on- and off-intervals of the driver. During the on-interval (from $\mathrm{t}=0 \mathrm{~s}$ to $150 \mathrm{~s}$ ), the device without control takes $100 \mathrm{~s}$ to settle to the targeted temperature. The transient response of the controlled device is magnified as shown in the bottom inset. Observably, the response has only $3 \%$ overshoot, and settles in $16 \mathrm{~s}$, which is 16 times faster than that of the uncontrolled device.

Practical result also pronounces the delay of $0.8 \mathrm{~s}$ compared with the simulated response. The delay is due to the sampling, data-conversion and instruction-execution processes taken by the digital control loop. This delay could be further reduced using an appropriate control or a higher performance CPU if necessary. Response during the beginning of the off-interval $(\mathrm{t}=150 \mathrm{~s}$ to $155 \mathrm{~s})$ is also magnified as shown in the top right inset. The fall-time is considerably long because the device dissipates heat naturally. However, this long thermal decay rate could be reduced via some added-on components to help dissipate heat.

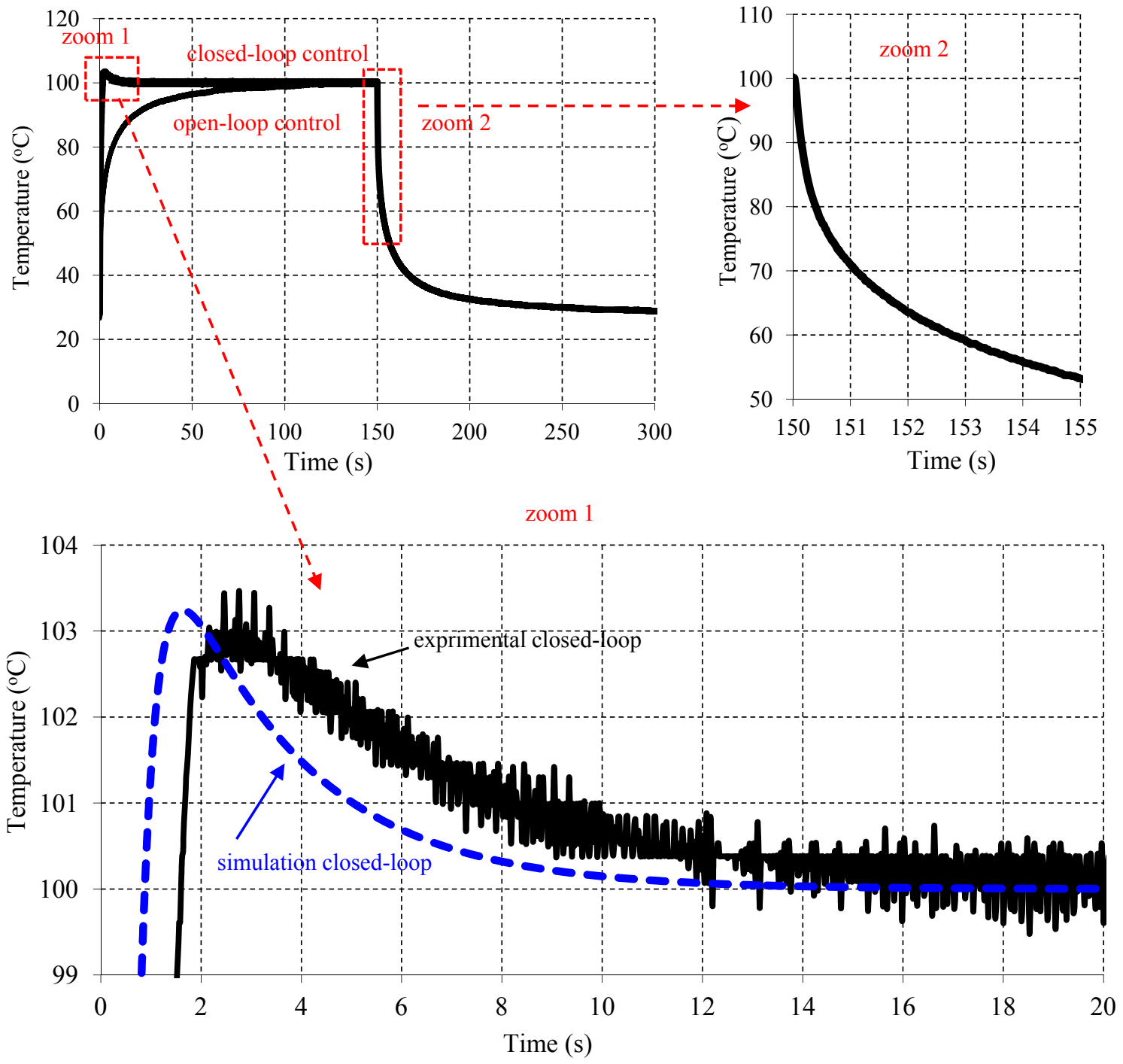

Figure 11. Closed-loop experimental response of the microheater

Figure 12 shows the controlled temperature variation based on 5 temperature targets widely used in microfluidic applications. It can be observed that the temperature quickly responds when the system was actuating to high temperature. In the other hand, the responses of cool down states do not provide suitable variations, especially a change of temperature from $60^{\circ} \mathrm{C}$ to $40^{\circ} \mathrm{C}$. 


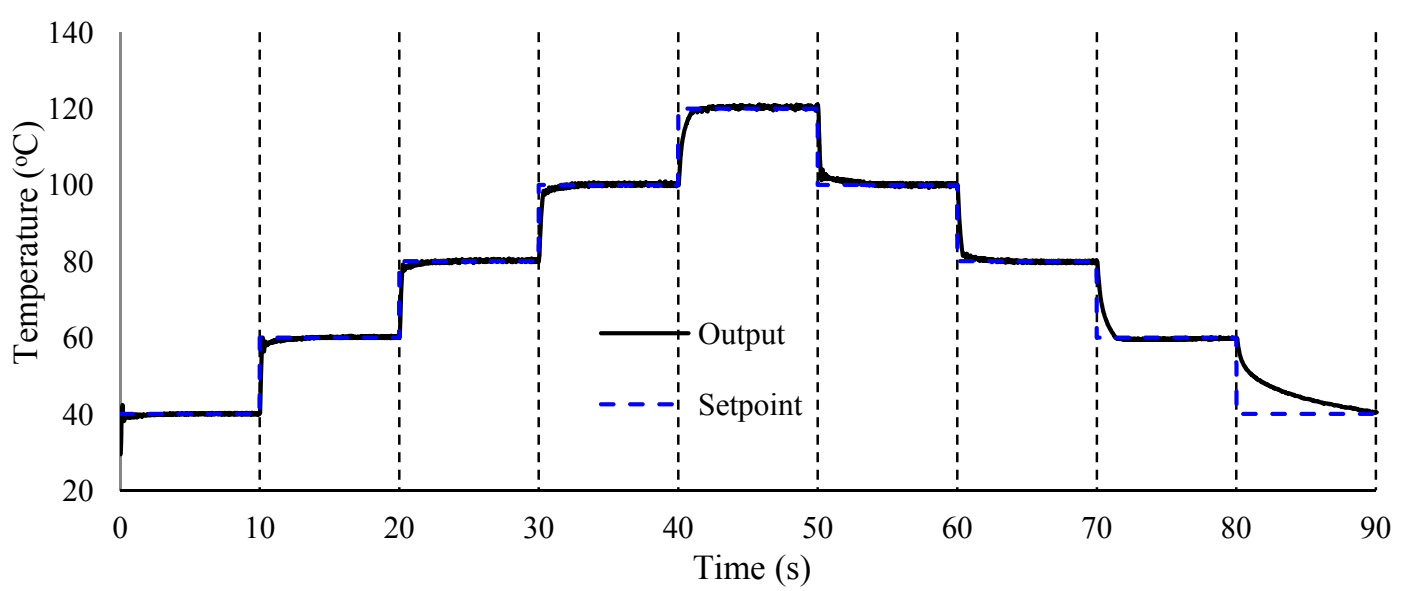

Figure 12. The controlled temperature variation based on 5 different temperature targets

In the fabrication process of sensors and heaters many works used chemical etching process, RIE process, and PECDV/LPCVD process to fabricate such devices. These processes are very expensive and even the cost of manufacturing is also high. This work uses lithography process and lift-off technique. However, in which the machine and equipment are not expensive and the cost of the device is not too high. On the other hand, it requires more steps in order to finish the process.

In generally, the metal thin-film of sensor and microheater is fabricated by using Au and Pt since both materials are reliable and can operate at high temperature. Specifically, Pt can operate at high temperature more than $800^{\circ} \mathrm{C}$. It has very good linearity and performance but is 10000 times more expensive than $\mathrm{Al}$ and Ni. In future work, this research plans to apply to miniature PCR operating at less than $100^{\circ} \mathrm{C}$. Therefore, this work must use $\mathrm{Al}$ and $\mathrm{Ni}$ since both materials are not expensive and easy to purchase in market. Additionally, $\mathrm{Al}$ and $\mathrm{Ni}$ are appropriate to fabricate as a heater-sensor set because they have good linearity at low temperature.

For temperature control microheater is operated in a few types for testing. The first type is the openloop control in which a power apply is use to generate thermal energy and it is easy to use. Howerver, this type cannot control temperature at the level of setting target constantly since there is no feedback signal sent to a controller. Many researches use the second type which is a closed-loop control. The closed-loop utilizes ON-OFF control which is easy to program in this software. The disadvantage of it is the oscillation of temperature. Nevertheless, it is better than the open-loop control. In some cases, PI/PID controllers are used in the closed-loop control. Since there is no strict mathematical model for calculating controller parameters it must take some time in tuning parameters or finding controller gains. Furthermore it cannot predict the response time of the overall system. In this research, a closed-loop PI controller is chosen and the mathematical model is calculated from real experiments with ARMAX method which is the first research for microheater and MEMS devices. This method helps to design parameters of the control systems and the temperature control is very accurate than the system without closed-loop control.

\section{CONCLUSION}

Design and fabrication processes of the low-cost controlled temperature microheater set were presented. Photolithography method was used for $\mathrm{Al}$ microheater and $\mathrm{Ni}$ sensor patterning designed to monitor and control the temperature. By surrounding Ni sensor with Al microheater while microheater was energized, temperature change can be rapidly checked and fed-back to control the input power using PI closed-loop control. The PI controller was adjusted to achieve the step response for the controlled temperature between $40^{\circ} \mathrm{C}$ and $120^{\circ} \mathrm{C}$. As the result, the PI closed-loop control is 16 times faster than the open-loop control and response has only $3 \%$ overshoot. Nevertheless, thermal decay has to be considered more based on fabrication materials and some add-on electronic components for heat dissipation.

\section{ACKNOWLEDGMENTS}

We are grateful to the Synchrotron Light Research Institute (Public Organization) for grating a valuable scholarship and giving an opportunity to perform device processing. 


\section{REFERENCES}

[1] G. S. Chung and J. M. Jeong, "Fabrication of micro heaters on polycrystalline 3C-SiC suspended membranes for gas sensors and their characteristics," Microelectron Engineering, vol. 87, pp. 2348-2352, 2010.

[2] I. S. Hwang, ea al., "Gas sensing properties of $\mathrm{SnO} 2$ nanowires on micro-heater," Sensors Actuators B, vol. 154, pp. 295-300, 2009.

[3] J. H. Yoon and J. S. Kim, "Study on the MEMS-type gas sensor for detecting a nitrogen oxide gas," Solid State Ion, vol. 192, pp. 668-671, 2010.

[4] W. J. Hwang, ea al., "Development of micro-heaters with optimized temperature compensation design for gas sensors," Sensors, vol. 11, pp. 2580-2591, 2011.

[5] S. K. Nam, ea al., "Design and characterization of a high resolution microfluidic heat flux sensor with thermal modulation," Sensors, vol. 10, pp. 6594-6611, 2010.

[6] T. Guan and R. Puers, "Thermal Analysis of a Ag/Ti Based Microheater," in Proceedings of EurosensorsXXIV, Linz, Austria, 5-8 September 2010, pp. 1356-1359.

[7] K. L. Zhang, ea al., "Fabrication, modeling and testing of a thin film Au/Ti microheater," International Journal of Thermal Sciences, vol. 46, pp. 580-588, 2007.

[8] C. Y. Lee, ea al., "High-performance MEMS-based gas chromatography column with integrated micro-heater," in Symposium on Design Test Integration and Packaging of MEMS/MOEMS, Seville, Spain, 5-7 May 2010.

[9] D. Briand, ea al., "Polymeric hotplates for sensors and actuators," EurosensorsXIX, pp. TB15, 2005.

[10] J. F. Creemer, ea al., "Microhotplates with TiN heaters," Sensors Actuators A, vol. 148, pp. 416-421, 2008.

[11] Z. X. Cai, ea al., "Fabrication of platinum microheater on alumina substrate by micro-pen and laser sintering," Thin Solid Films, vol. 519, pp. 3893-3896, 2011.

[12] Z. X. Cai, ea al., "Fabrication of microheater by laser micro cladding electronic paste," Materials Science and Engineering B, vol. 157, pp. 15-19, 2009.

[13] D. S. Yoon, ea al., "Precise temperature control and rapid thermal cycling in a micromachined DNA polymerase chain reaction," Journal of Micromechanics and Microengineering, vol. 12, pp. 813-823, 2002.

[14] W. Wang, ea al., "Droplet-base micro oscillating-flow PCR chip," Journal of Micromechanics and Microengineering, vol. 15, pp. 1369-1377, 2005.

[15] C. Y. Lee, ea al., "Integrated microfluidic systems for cell lysis, mixing/pumping and DNA amplification," Journal of Micromechanics and Microengineering, vol. 15, pp. 1215-1223, 2005.

[16] Z. Q. Niu, ea al., "DNA amplification on a PDMS-glass hybrid microchip," Journal of Micromechanics and Microengineering, vol. 16, pp. 425-433, 2006.

[17] M. P. Dinca, ea al., "Fast and accurate temperature control of a PCR microsystem with a disposable reactor," Journal of Micromechanics and Microengineering, vol. 19, pp. 1-15, 2009.

[18] Z. Q. Zou, ea al., "A novel miniaturized PCR multi-reactor array fabrication using flip-chip boding techniques," Journal of Micromechanics and Microengineering, vol. 15, pp. 1476-1481, 2005.

[19] D. S. Lee, ea al., "A disposable plastic-silicon micro PCR chip using flexible printed circuit board protocols and its application to genomic DNA amplification," IEEE Sensors Journal, vol. 8, pp. 558-564, 2008.

[20] W. Mamanee, ea al., "PDMS base thermopnumatic peristaltic micropump for microfluidic systems," Journal of Physics Conference Series, vol. 34, pp. 564-569, 2006.

[21] Y. J. Yang and H. H. Liao, "Development and characterization of thermopneumatic peristaltic micropumps," Journal of Micromechanics and Microengineering, vol. 19, pp. 1-13, 2009.

[22] O. C. Jeong, ea al., "Fabrication of peristatal PDMS Micropump," Senser Aactuator A, vol.123-124, pp. 453-458, 2005.

[23] R. Phattanakun, "Design and Fabrication of Thin-Film Aluminum Microheater and Nickel Temperature Sensor," in Proceedings of The 7th IEEE international conference on Nano/Micro Engineered and Molecular Systems (IEEENEMS 2012), Kyoto, Japan, 5-8 March, 2012.

[24] B. Carter and R. Mancini, "OP AMPS for Everyone," 3rd ed., Elsevier Inc, 2009.

[25] L. Ljung, "System Identification Toolbox for MATLAB: User’s Guide Version 6,” Mathworks Inc., 2003.

[26] C. L. Phillips and R. D. Harbor, "Feedback control system," 4th ed., Prentice Hall, 2000. 